\title{
The Marginated Pool
}

\author{
Wolfgang M. Kuebler a,b Alwin E. Goetz ${ }^{c}$ \\ a Institute of Physiology, Free University of Berlin, bInstitute of Anesthesiology, Deutsches Herzzentrum Berlin, and \\ 'Department of Anesthesiology, University of Munich, Germany
}

\section{Key Words}

Pulmonary microcirculation - Marginated pool of leukocytes · Intravital microscopy · Alveolar capillaries · Regulation of microvascular flow · Adhesion molecules

\begin{abstract}
The pulmonary circulation harbors a large intravascular reservoir of leukocytes refered to as the Marginated Pool. This marginated pool is balanced by propeling and retaining forces acting on leukocytes during their passage through the pulmonary circulation. The present paper discusses these factors and their underlying mechanisms.
\end{abstract}

Copyright (C2002 S. Karger AG, Basel

\section{Introduction}

The last decade has witnessed the emerging role of leukocytes not only in host defense, but also in the pathogenesis of numerous diseases and tissue injury. This notion puts the physiological characteristics of leukocyte kinetics into a new perspective. Of particular interest are factors controling the number of circulating leukocytes in the blood, and the physiological compartmentalization of white blood cells in the body. This review discusses the importance of the pulmonary microcirculation as a natural reservoir where leukocytes are temporarily sequestered from the circulating blood, but can be rapidly mobilized in times of need. This reservoir is referred to as the Marginated Pool, since initially leukocytes were believed to leave the circulating blood stream by taking a marginal position in the pulmonary blood vessels.

\section{Early Studies}

In 1910, F.W. Andrewes delivered the Croonian lecture series to the Royal College of Physicians in London, which were published in two parts in the Lancet $[1,2]$. Whereas his first two lectures discussed the role of leukocytes in host defense, the third and fourth focussed on the distribution of leukocytes in the organism. From his own histological studies in rabbits, as well as from the earlier work of D. Bruce [3], A. Goldscheider and P. Jacob [4], he realized that the lung harbors more leukocytes within its microvascular network than any other organ. He speculated that their sojourn in the lung was for the sake of oxygenation, and stated that 'It may be that the bone marrow is the birthplace of these cells and the spleen their ultimate tomb, while the blood is their means of transit, the lung may serve as a weekend at the seaside'. Thus, he first described the marginated pool, and although its relevance was obscure to Andrewes, he believed it to be of 'deep physiological significance'.

\section{Cardiac Catheterization Studies}

The development of cardiac catheterization [5] and its introduction into clinical practice [6] provided new insights into the marginated pool and its dynamic control. By comparison of the leukocyte concentrations in simul-

\section{KARGER \\ Fax +4161306 1234 \\ E-Mail karger@karger.ch \\ www. karger.com

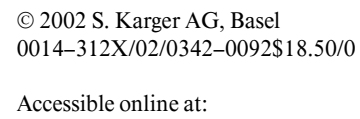

Priv.-Doz. Dr. W.M. Kuebler

Institute of Physiology, Free University of Berlin

Arnimallee 22, D-14195 Berlin (Germany)

Tel. +49 308445 1638, Fax +49 3084451634

E-Mail kuebler@zedat.fu-berlin.de 
taneously drawn blood samples from the right heart and the brachial or femoral artery, respectively, Bierman and associates assessed the regulation of the marginated pool [7]. They observed that the Valsalva maneuver or infusion of histamin increased pulmonary leukocyte sequestration [8, 9], whereas leukocytes were released from the marginated pool by the Mueller maneuver or infusion of epinephrine $[8,10]$. From these data, they concluded that the marginated pool is not a stationary phenomenon, but that leukocytes may become sequestered in and released from the lung microcirculation in a dynamic process.

\section{Radioisotope Studies}

Radiolabeling of leukocytes was first performed in 1959 by use of the radiolabeled cholinesterase inhibitor diisopropyl fluorophosphate ([ $\left.\left.{ }^{32} \mathrm{P}\right] \mathrm{DFP}\right)$ and allowed for a more thorough investigation of the dynamic regulation of the marginated pool [11]. By use of a double indicator dilution technique with labeled polymorphonuclear granulocytes (PMN) and erythrocytes, Martin et al. determined that $80-90 \%$ of the labeled PMN become sequestered in the canine pulmonary circulation during their first passage [12]. However, since the concentration of PMN did not diverge between arterial and venous blood, the authors concluded that a similar number of PMN must simultaneously have been released from the lung. Hence, the circulating and marginating pools of leukocytes in the lung form a dynamic equilibrium. Similar PMN sequestration rates of 88,83 and 74\% were determined in porcine and rabbit lungs, respectively [13-15], but were reported as low as $5-15 \%$ in humans $[16,17]$. These findings caused some controversy, until Hogg et al. were able to attribute this discrepancy to the indirect measurement of radionuclides in human studies rather than to species differences [18]. Additional radioisotope studies revealed that the marginated pool equals or even exceeds the pool of circulating PMN [15, 19, 20] and exchanges with the latter at a rate of $1.5 \pm 0.5 \%$ per second [15].

However, it has to be considered that separation and radiolabeling procedures may activate leukocytes and alter their kinetics [21-23]. Moreover, radiolabeled PMN studies cannot provide insight into the local microvascular distribution of PMN and mechanisms regulating the marginated pool.

\section{Intravital Microscopic Studies}

Intravital microscopy provides the highest spatial and temporal resolution of dynamic microvascular processes such as leukocyte margination. The first microscopic studies of the pulmonary microcirculation were performed by Malpighi in 1661 in the frog lung [24]. A thoracic window technique enabling visual access to the lung under closed thorax conditions was developed by Terry in 1939 [25] and subsequently modified by Wagner et al. for the study of lung microvascular hemodynamics [26, 27]. By use of this technique, Lien et al. visualized the passage of PMN labeled in vitro by fluorescein-isothiocyanate (FITC) through the subpleural capillary networks of the canine lung [28]. They observed, that PMN get retained during their passage through the alveolar capillary network and concluded, that the marginated pool is exclusively localized in the pulmonary capillary bed [29].

In order to assess leukocyte kinetics not only in alveolar capillaries, but simultaneously in pulmonary arterioles and venules under consideration of macrohemodynamic as well as local microhemodynamic conditions, we developed a model to visualize the kinetics of fluorescentlylabeled red and white blood cells in the different microvascular compartments of the rabbit lung [30, 31]. Under general anesthesia, a steel window with a transparent teflon membrane at its basis is implanted into the right thoracic wall and provides visual access to the surface of the right lung (fig. 1). Intravital fluorescence microscopy enables the visualization and kinetic analysis of leukocytes labeled in vivo by rhodamine 6G [32] and erythrocytes stained in vitro by FITC [33] during their transit through the pulmonary microcirculation.

By use of this model, we determined that the intravascular concentration of leukocytes is significantly elevated in all compartments of the pulmonary microcirculation as compared to arterial blood $[31,34]$, indicating that leukocyte margination is a prominent feature not only in alveolar capillaries, but also in pulmonary arterioles and venules (fig. 2). However, since the vascular surface area of the alveolar capillary network exceeds the combined surface areas of pulmonary arterioles and venules by 20 - to 30 -fold [35, 36], the predominant localization of the marginated pool is indeed the capillary bed (fig. 3) [37].

\section{Retention in Alveolar Capillaries}

When passing through alveolar capillaries, leukocytes become frequently retained for varying time periods and

Eur Surg Res 2002;34:92-100 
Fig. 1. Thoracic window for intravital microscopic studies of the rabbit lung microvasculature. The window, consisting of a hollow steel cylinder with a transparent teflon membrane at its basis, is implanted into the left thoracic wall following partial resection of the $3 \mathrm{rd}$ and 4 th rib. Negative pressure of 0.4 bar is applied via 16 boreholes and fixes the lung surface to the window. To avoid drying or cooling of the lung surface, the window is continuously superfused with a gas-equilibrated tyrode buffer at $37^{\circ} \mathrm{C}$.

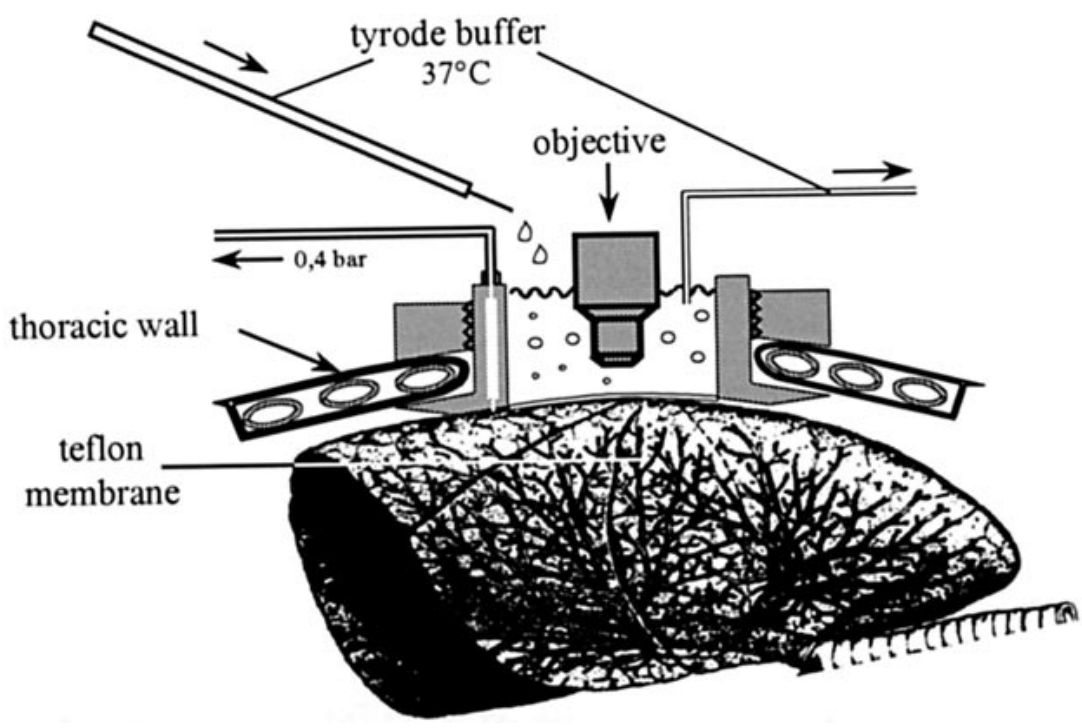

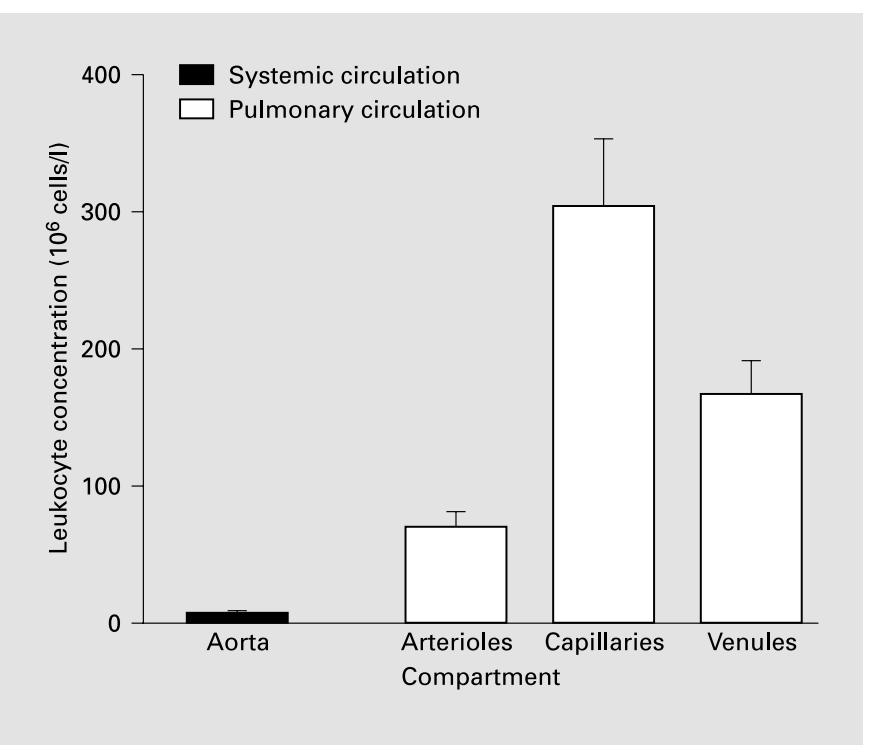

Fig. 2. Leukocyte concentration in different compartments of the pulmonary microcirculation as compared to arterial blood. Data determined by intravital microscopy as presented in [31].

then continue their passage through the pulmonary circulation $[29,38]$. These temporary stops generally last $<1 \mathrm{~s}$, but may occasionally exceed $1 \mathrm{~min}$ or more [29, 31]. However, since more than $90 \%$ of passing leukocytes become retained at least once during their transit through the lung, these stops are a frequent phenomenon, and occlude up to $15 \%$ of alveolar capillaries [38].

Doerschuk et al. attributed this retention to a local disproportion between the capillary diameters of the pulmonary microvasculature and the mean diameter of circulating PMNs since a substantial number of lung capillary segments exhibit diameters distinctly smaller than the mean leukocyte diameter [39]. Since the average capillary segment length is $8 \mu \mathrm{m}$ [40] and the average pathway from precapillary arterioles to postcapillary venules is $800 \mu \mathrm{m}$ [41], a leukocyte must traverse at least 100 capillary segments during each pulmonary transit. If only $1-2 \%$ of these capillaries mechanically impede leukocyte transit, $55-60 \%$ of the traversing leukocytes will be temporarily retained [42]. In order to pass these narrow capillary segments, leukocytes have to deform from a spherical into an elongated shape [43]. Although PMN have a mean diameter similar to that of erythrocytes and are able to rapidly deform to effective diameters of 5.0-5.1 $\mu \mathrm{m}$ [44], their further deformation to effective diameters as small as $2.6 \mu \mathrm{m}$ [45] is by a factor 1,000 slower as compared to red blood cells [46, 47]. Hence, their capillary passage is delayed and they accumulate until their deformation suffices to re-enter the circulating pool.

It may seem ominous that a single organ is able to harbor such an enormous number of marginated cells in its capillary bed without impairment of its macro- or microhemodynamic perfusion and function. This reservoir ca- 
Fig. 3. Total cell number of the circulating and marginated leukocyte pool, and its distribution in different compartments of the pulmonary microcirculation. Calculated from morphometric data of the rabbit lung as described in [37].

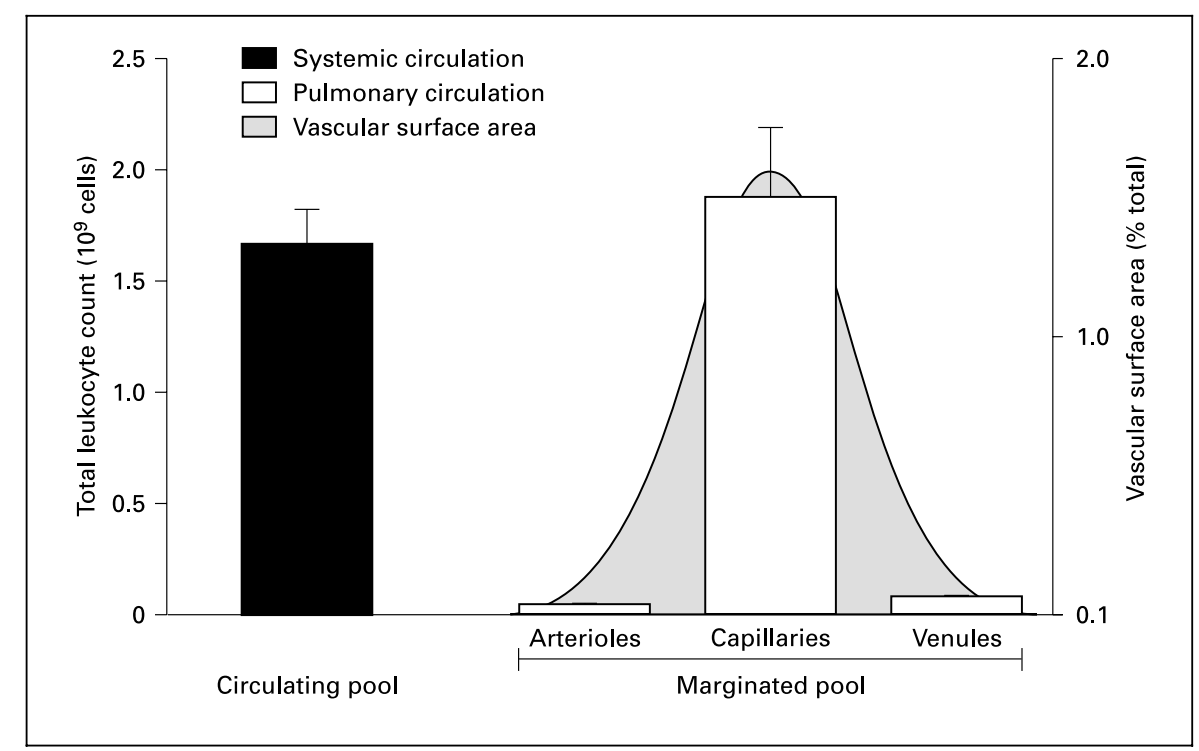

pacity is enabled by the unique functional geometry of the alveolar capillary network providing an abundance of parallel and interconnecting capillary pathways. Weibel has estimated that there are $277 \pm 22 \times 10^{9}$ capillary segments in the human lung ranging from $1-30 \mu \mathrm{m}$ in length [41]. Since $15 \%$ of capillary segments are occluded by marginated leukocytes [38], the human lung would then harbor a total marginated pool of approximately $42 \times 10^{9}$ cells, i.e. 1.5 times the total amount of circulating white blood cells. Even in much sparser capillarized networks such as in the spinotrapezius muscle, occlusion of $15 \%$ of capillary segments will increase total network resistance by less than $20 \%$ [48]. In the densely interwoven capillary network of the lung, this effect is further minimized. In addition, leukocytes tend to marginate preferentially in regional networks with a high density of capillary pathways and multiple cross-connections. These networks offer a multitude of patent capillary channels allowing for maintenance of alveolar blood flow despite excessive leukocyte margination [38]. These mechanisms minimize the effects of leukocyte margination on pulmonary perfusion, vascular resistance and lung function and make the lung capillary bed the ideal reservoir for the marginated pool.

\section{Margination in Arterioles and Venules}

Although the predominant localization of the marginated pool is the alveolar capillary network, leukocytes also accumulate in pulmonary arterioles and venules (fig. 2). In histologic examinations of sheep lungs, Staub et al. first detected marginated PMN in pulmonary arterioles [49]. They suggested that the cells may pile up on the arterial side of the capillary bed because of their difficulty in squeezing into the smallest microvessels. Using intravital microscopy, Koyama et al. noted leukocyte margination in both arterioles and venules of the bullfrog lung, but were unable to quantify their observations [50]. PMN margination in extracapillary lung microvessels was also confirmed histomorphologically by Hogg et al. [51] and Downey et al. [52], although both authors considered the phenomenon to be quantitatively negligible. Indeed, leukocyte margination in arterioles and venules contributes only little to the total marginated pool in the lung (fig. 3). Nevertheless, these phenomena might be of relevance, since various inflammatory processes originate predominantly from the arteriolar $[53,54]$ or venular $[55,56]$ compartments of the lung.

Margination in pulmonary arterioles and venules results from slow rolling of leukocytes along and firm adhesion to the microvascular wall $[31,34]$. These phemonena are characteristic features of leukocyte kinetics in postcapillary venules of the systemic circulation during inflammation, and were already described in the 19th century by Dutrochet [57] and Cohnheim [58]. However in arterioles of the systemic circulation, leukocyte margination is generally absent [59,60] and only occasionally observed under conditions of severe tissue injury [61]. In venules of the systemic circulation, leukocyte rolling, but not firm adhesion, are present under physiological condi- 
Fig. 4. Vertical gradient of regional pulmonary blood flow and neutrophil content in the rabbit lung in left lateral position. Regional perfusion (open squares) as assessed by the radioactive microsphere technique is given in percentage of perfusion per percentage of mass, neutrophil content was determined by an enzymatic myeloperoxidase assay. Figure adapted from data by Groh et al., Br J Anaesth 1995;74:209-216, and data from [67].

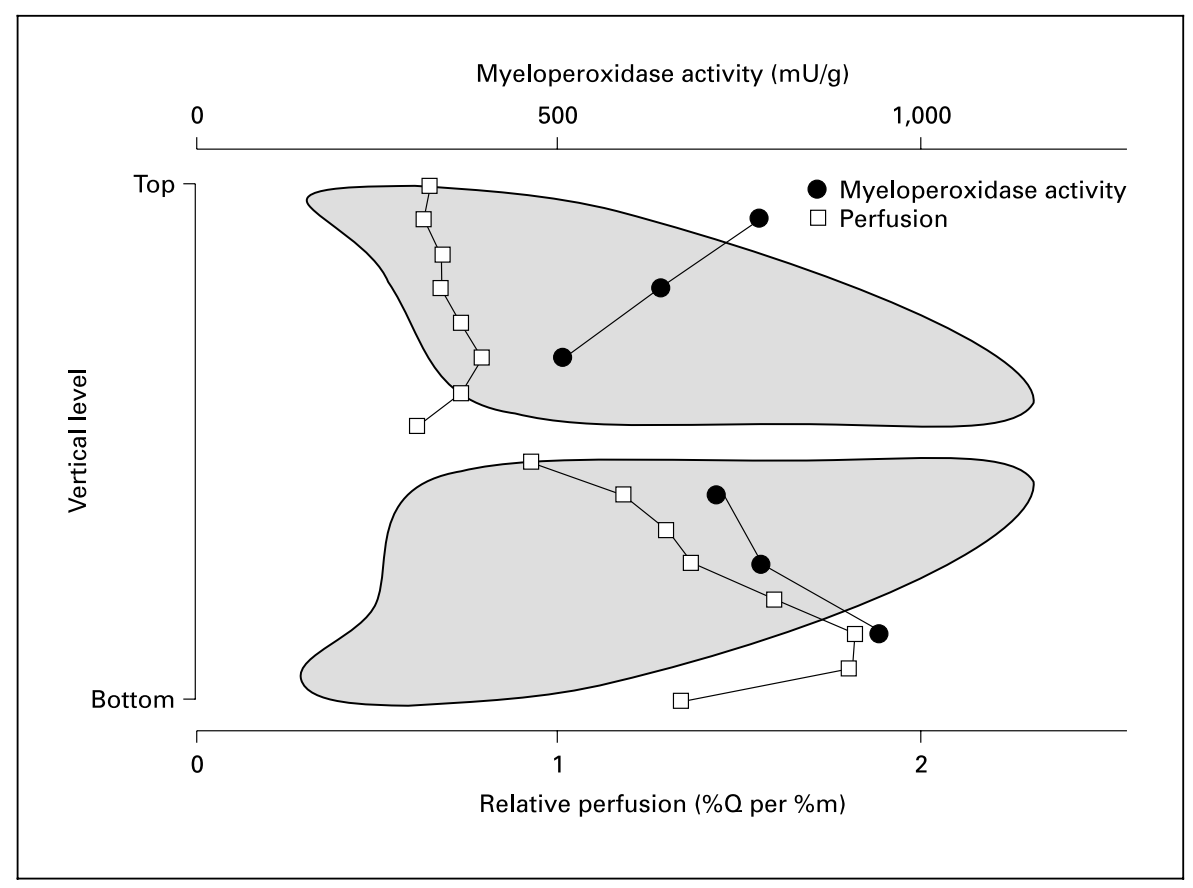

tions $[62,63]$. Hence, leukocyte margination by both rolling and adhesion in unstimulated arterioles and venules seems to be a unique feature of the pulmonary microcirculation.

\section{Regulation by Blood Flow}

The dynamic equilibrium of the marginated pool is regulated by a balance of sequestering and mobilizing forces acting on each leukocyte. Already in 1952, Bierman et al. found that catecholamines may release leukocytes from the marginated pool [10]. Subsequent studies showed a similar response to exercise [17]. Martin et al. elegantly demonstrated that these effects are predominantly attributable to an increase in cardiac output [12]: In the canine lung, elevation of cardiac output by implantation of a large arterio-venous shunt released leukocytes from the marginated pool, whereas reduction of pulmonary blood flow by an inflatable balloon catheter in the vena cava promoted pulmonary leukocyte margination. In our intravital microscopic studies, we determined an inverse relationship between the microvascular shear rate and the amount of leukocyte rolling and adhesion in pulmonary arterioles and venules [34]. Hence, shear forces exerted by microvascular blood flow counteract leukocyte-endothelial cell interactions and therefore release leukocytes from the marginated pool. Similarly in alveolar capillaries, leukocyte retention in narrow capillary segments is prolonged when microvascular blood flow velocity and hence, shear forces are reduced [64]. This notion is in accordance with in vitro data demonstrating an inverse logarithmic relationship between applied shear stress and the retention of leukocytes in $5 \mu \mathrm{m}$ Nuclepore filters [65].

Microvascular blood flow is not only the major force releasing leukocytes from the marginated pool, but also regulates its regional distribution. As discussed above, leukocytes tend to marginate preferentially in regional networks with a high density of capillary pathways and multiple cross-connections. These networks are characterized by a low microvascular blood flow velocity and hence, low shear forces acting on the retained blood cells, whereas shear forces are high in less densely capillarized areas and thus rapidly squeeze leukocytes through the capillary segments [38]. In addition, the typical regional distribution of pulmonary perfusion [66] determines the characteristic vertical gradient of PMN margination in the lung (fig. 4). Margination is most prominent in the dependent, hypostatic lung zones where capillary networks are fully recruited and thus harbor a large number of retained cells [67]. However, this gravitational gradient is opposed by an enhanced retention of PMN in upper lung regions [20] due to low regional blood flow [15] and 
Fig. 5. Adhesion molecules mediating leukocyte-endothelial cell interactions. Selectincarbohydrate interactions facilitate leukocyte rolling, interaction of integrins with adhesion molecules of the immunoglobulin family (IgCAMs) mediates firm adhesion, while CD31 and $\alpha_{v} \beta_{3}$-integrins contribute to leukocyte emigration.

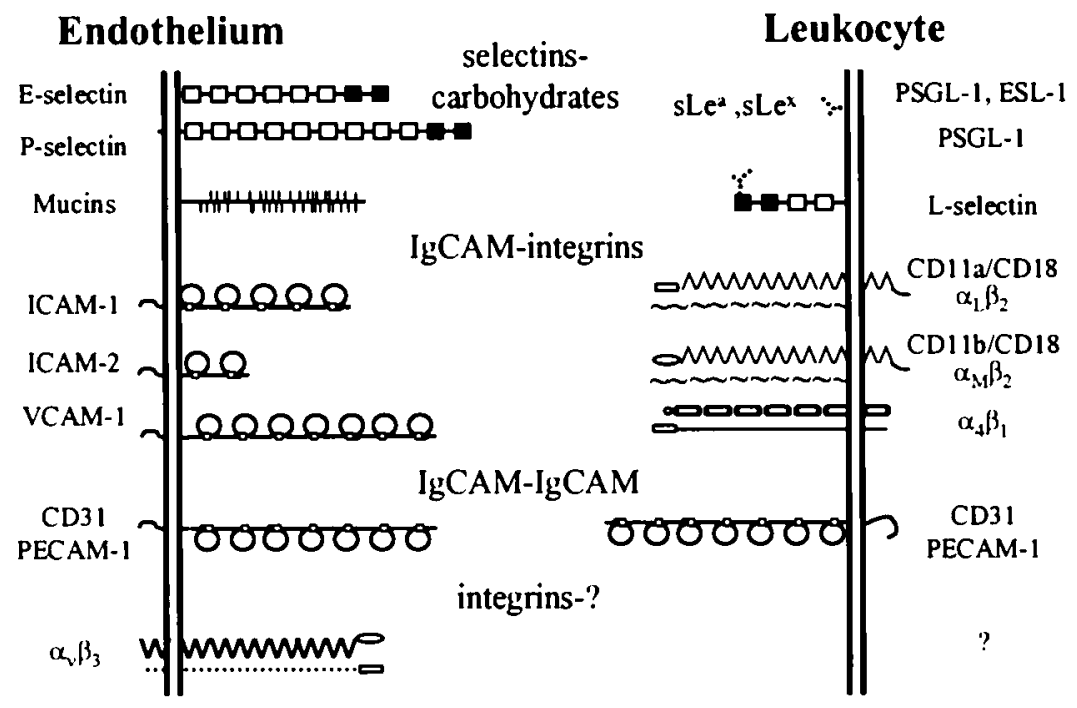

small capillary diameters [44]. Finally, reduction of pulmonary blood flow is at least partially responsible for the well-recognized phenomenon that elevation of airway pressure increases leukocyte margination [68]. Positive pressure ventilation reduces microhemodynamic blood flow predominantly in apical lung zones, and simultaneously promotes leukocyte rolling and adhesion in pulmonary arterioles and venules, and leukocyte retention in alveolar capillaries [69]. This effect is of particular clinical relevance since patients with leukocyte-mediated acute lung injury are frequently ventilated with high positive airway pressures, which will promote additional leukocyte recruitment into the lungs.

\section{Adhesion Molecules}

The adhesion cascade of leukocytes in inflamed venules of the systemic circulation has been well-characterized over the last decade and comprises leukocyte rolling mediated by adhesion molecules of the selectin family and firm adhesion mediated by the interaction of leukocyte integrins with endothelial counterligands of the immunoglobulin family (fig. 5). In the pulmonary circulation, leukocyte rolling and adhesion are also present under baseline conditions, but more prominent in pulmonary venules as compared to arterioles [31, 34]. Yet under zone 2 conditions [66], blood flow velocities in pulmonary venules equal or even exceed those in arterioles due to the vascular waterfall effect [70, 71]. Hence, the differential margination in arterioles and venules cannot be attributed to microhemodynamic factors, but presumably reflects divergent adhesive properties of the microvascular endothelium. By use of the unspecific selectin inhibitor fucoidin [72] we identified selectin-mediated interactions as major cause of leukocyte rolling in pulmonary arterioles and venules under baseline conditions [73]. Indeed, Pselectin is expressed in unstimulated pulmonary microvessels, but predominantly confined to the venular compartment [55]. In contrast, inhibition of L-selectin by a specific antibody does not affect pulmonary leukocyte kinetics at baseline, suggesting that unstimulated leukocyte rolling in lung mircovessels is mediated by $\mathrm{P}-$, not L-selectin [74].

Selectins not only mediate leukocyte rolling in pulmonary arterioles and venules, but also contribute to leukocyte retention in alveolar capillaries, indicating that both mechanical hindrance and leukocyte-endothelial cell interactions contribute to leukocyte margination in capillary networks [73]. However, the selectin inhibitor fucoidin does not affect firm adhesion of leukocytes indicating that additional adhesion molecules contribute to leukocyte margination in the lung. Indeed, the lung microvascular endothelium constitutively expresses a high amount 
of the adhesion molecule ICAM-1 [75], which serves as counterreceptor for leukocyte $\beta_{2}$-integrins and mediates firm adhesion during inflammation in the systemic circulation [76]. Hence, $\beta_{2}$-integrins are likely candidates as mediators of the firm adhesion of leukocytes in pulmonary arterioles and venules and may even contribute to leukocyte retention in capillaries. Nagawaka et al. noted that a single bolus infusion of dexamethasone induces a granulocytosis by releasing PMN perdominantly from the marginated pool [77]. Since bolus injections of glucocorticoids have little effect on pulmonary hemodynamics [78], but downregulate the CD18 expression on PMN [79], $\beta_{2-}$ integrin mediated leukocyte-endothelial cell interaction seems to be an additional mechanism contributing to leukocyte margination in the lung. This notion is also supported by the finding that PMN released from the marginated pool during acute maximal exercise express higher levels of $\mathrm{CD} 11 \mathrm{~b} / \mathrm{CD} 18$ integrins as compared to circulating PMN [80].

\section{Summary}

The pulmonary microcirculation acts as a natural reservoir of leukocytes generally referred to as the Marginated Pool. This pool exceeds the total circulating pool of leukocytes and exchanges constantly with the latter in a dynamic equilibrium. The marginated pool is predominantly localized in the dense alveolar capillary networks, but leukocytes also accumulate in pulmonary arterioles and particularly in venules by rolling and firm adhesion. Leukocyte reten- tion in the alveolar capillaries is largely attributable to the specific anatomy of the pulmonary microcirculation, which is made up of a dense and interwoven network of a large number of capillary segments many of which have diameters smaller than leukocytes. Hence, leukocytes have to deform to squeeze through these narrow vessel segments and therefore accumulate temporarily in the lung. Due to the abundancy of capillary pathways, this accumulation produces little hindrance to erythrocyte blood flow. In addition, adhesion molecules both of the selectin and integrin families mediate leukocyte-endothelial cell interactions in unstimulated pulmonary arterioles, capillaries and venules and contribute to leukocyte margination. The mechanisms of leukocyte margination are counterbalanced by the propeling force exerted by pulmonary blood flow, which may release leukocytes from the marginated pool under conditions of increased cardiac output.

The question remains as wether the marginated pool provides a phylogenetic benefit - does it serve as natural reservoir of immunocompetent cells to be rapidly released under stress, is it a local defence mechanism of the lung to protect the large alveolar surface area from invading microbes, or does it act as a sponge withdrawing aged or apoptotic leukocytes from the circulation? Although its physiological relevance remains enigmatic, this compartmentalized distribution of leukocytes within the organism is pathophysiologically important. Since activated leukocytes can damage normal tissue and will exert this effect particularly at sites where large numbers of leukocytes are accumulated, the marginated pool renders the lung particularly prone to leukocyte-mediated tissue injury.

\section{Acknowledgment}

We are indebted to Professor Konrad Messmer. For many years, his continuous support enabled our studies, from his valuable critiques we learned and progressed.

\section{References}

1 Andrewes FW: The behaviour of the leucocytes in infection and immunity. Lecture I. Lancet 1910;i:1737-1743.

2 Andrewes FW: The behaviour of the leukocytes in infection and immunity. Lecture II. Lancet 1910;ii:8-16.

3 Bruce D: The disappearance of the leukocytes from the blood after injecton of peptone. JR Soc Med 1894;294-299.

4 Goldscheider A, Jacob P: Über die Variationen der Leukocytose. Z Klin Med 1894;25:373448.

5 Forssmann W: Münchener Medizinische Wochenschrift/20 March 1931: Contrast representation of the cavities of the living right half of the heart by Werner Forssmann, Eberswalde. MMW 1978;120:489.

6 Cournand A, Baldwin JS, Himmelstein A: Cardiac catheterization in congenital heart disease. New York, Commonwealth Fund, 1949.

7 Bierman HR, Byron RL Jr, Kelly KH, Petraki NL: The lung removal mechanism for leukocytes. Blood 1951;6:770-771.
8 Bierman HR, Kelly KH, Cordes FL, Petrakis NL, Kass H, Shpil EL: The influence of respiratory movements upon the circulating leukocytes. Blood 1952;7:533-544.

9 Bierman HR, Kelly KH, Petrakis NL, Cordes F, Foster M, Lose EA: The effect of intravenous histamine administration on the level of the white blood count in the peripheral blood. Blood 1951;6:926-935.

10 Bierman HR, Kelly KH, Cordes FL, Byron RL Jr, Polhemus J, Rappoport S: The release of leukocytes and platelets from the pulmonary circulation by epinephrine. Blood 1952;7:683692.

11 Athens JW, Mauer AM, Ashenbrucker H, Cartwright GE, Wintrobe MM: Leukocyte kinetic studies. I. A method for labelling leukocytes with diisopropylfluorophosphate (DFP ${ }^{32}$ ). Blood 1959;14:303-333.
12 Martin BA, Wright JL, Thommasen H, Hogg JC: Effect of pulmonary blood flow on the exchange between the circulating and marginating pool of polymorphonuclear leukocytes in dog lungs. J Clin Invest 1982;69:12771285 .

13 Ohgami M, Doerschuk CM, English D, Dodek PM, Hogg JC: Kinetics of radiolabeled neutrophils in swine. J Appl Physiol 1989;66:18811885.

14 Schütte H, Rosseau S, Walmrath D, Grimminger F, Ernst C, Seeger W: Neutrophil passage through isolated perfused rabbit lungs. Am J Physiol 1991;261:H1317-H1323.

15 Doerschuk CM, Allard MF, Martin BA, MacKenzie A, Autor AP, Hogg JC: Marginated pool of neutrophils in rabbit lungs. J Appl Physiol 1987;63:1806-1815.

16 MacNee W, Wiggs B, Belzberg AS, Hogg JC: The effect of cigarette smoking on neutrophil kinetics in human lungs. N Engl J Med 1989; 321:924-928. 
17 Muir AL, Cruz M, Martin BA, Thommasen H, Belzberg A, Hogg JC: Leukocyte kinetics in the human lung: Role of exercise and catecholamines. J Appl Physiol 1984;57:711-719.

18 Hogg JC, Doerschuk CM, Wiggs B, Minshall $D$ : Neutrophil retention during a single transit through the pulmonary circulation. J Appl Physiol 1992;73:1683-1685.

19 Athens JW, Haab OP, Raab SO, Mauer AM, Ashenbrucker H, Cartwright GE, Wintrobe MM: Leukocyte studies. IV. The total blood, circulating and marginated granulocyte pools and the granulocyte turnover rate in normal subjects. J Clin Invest 1961;40:989-995.

20 Martin BA, Wiggs BR, Lee S, Hogg JC: Regional differences in neutrophil margination in dog lungs. J Appl Physiol 1987;63:1253-1261.

21 Forsyth K, Levinsky R: Preparative procedures of cooling and rewarming increase leukocyte integrin expression and function on neutrophils. J Immunol Meth 1990;128:159-163.

22 Haslett C, Guthrie LA, Kopaniak MM, Johnston RB, Henson PM: Modulation of multiple neutrophil functions by preparative methods or trace concentrations of bacterial lipopolysaccharide. Am J Path 1985;119:101-110.

23 Saverymuttu SA, Peters AM, Danpure HJ, Reavy HJ, Osman S, Lavender JP: Lung transit of ${ }^{111}$ indium labelled granulocytes: Relationship to labelling techniques. Scand J Haematol 1983;30:151-160.

24 Malpighi M: De pulmonibus, Epistle II. Bologna, 1661, Translation by J. Young. Proc Roy Soc Med 1929;23:7.

25 Terry RJ: A thoracic window for observation of the lung in a living animal. Science 1939;90: 43-44.

26 Wagner WW, Latham LP, Gillespie MN, Guenther JP: Direct measurement of pulmonary capillary transit times. Science 1982;218: 379-381.

27 Wagner WW, Filley GF: Microscopic observation of the lung in vivo. Vasc Dis 1965;2:229_ 241.

28 Lien DC, Wagner WW, Capen RL, Haslett C, Hanson WL, Hofmeister SE, Henson PM, Worthen GS: Physiological neutrophil sequestration in the lung: Visual evidence for localization in capillaries. J Appl Physiol 1987;62. 1236-1243.

29 Lien DC, Worthen GS, Capen RL, Hanson WL, Checkley LL, Janke SJ, Henson PM, Wagner WW: Neutrophil kinetics in the pulmonary microcirculation. Effects of pressure and flow in the dependent lung. Am Rev Respir Dis 1990;141:953-959.

30 Kuhnle GEH, Leipfinger FH, Goetz AE: Measurement of microhemodynamics in the ventilated rabbit lung by intravital fluorescence microscopy. J Appl Physiol 1993;74:1462-1471.

31 Kuebler WM, Kuhnle GEH, Groh J, Goetz AE: Leukocyte kinetics in pulmonary microcirculation: Intravital fluorescence microscopic study. J Appl Physiol 1994;76:65-71.

32 Baatz H, Steinbauer M, Harris AG, Krombach F: Kinetics of white blood cell staining by intravascular administration of rhodamine $6 \mathrm{G}$. Int $\mathrm{J}$ Microcirc Clin Exp 1995;15:85-91.
33 Zimmerhackl B, Parekh N, Brinkhus H, Steinhausen M: The use of fluorescent labeled erythrocytes for intravital investigation of flow and local hematocrit in glomerular capillaries in the rat. Int J Microcirc Clin Exp 1983;2:119-129.

34 Kuhnle GEH, Kuebler WM, Groh J, Goetz AE: Effect of blood flow on leukocyte-endothelium interaction in pulmonary microvessels. Am J Respir Crit Care Med 1995;152:1221-1228.

35 Hogg JC: Neutrophil kinetics and lung injury. Physiol Rev 1987;67:1249-1295.

36 Siam S, Henderson R, Horsfield K, Harding K, Cumming G: Morphometry of the human pulmonary arterial tree. Circ Res 1973;23:190197.

37 Kuebler WM: In vivo Analyse der LeukozytenKinetik in der pulmonalen Mikrozirkulation. München, Hieronymus Buchreproduktions $\mathrm{GmbH}, 1997$.

38 Kuebler WM, Kuhnle GEH, Goetz AE: Leukocyte margination in alveolar capillary networks: Relationship to functional capillary morphology and microhemodynamics. J Vasc Res 1999;36:282-288.

39 Doerschuk CM, Beyers N, Coxson HO, Wiggs B, Hogg JC: Comparison of neutrophil and capillary diameters and their relation to neutrophil sequestration in the lung. J Appl Physiol 1993;74:3040-3045.

40 Staub NC, Schultz EL: Pulmonary capillary length in dog, cat and rabbit. Respir Physiol 1968;5:371-378.

41 Weibel ER: Morphometry of the human lung. New York, Academic Press, 1963.

42 Hanger CC, Wagner WW, Janke SJ, Lloyd TC, Capen RL: Computer simulation of neutrophil transit through the pulmonary capillary bed. J Appl Physiol 1993;74:1647-1652.

43 Gebb SA, Graham JA, Hanger CC, Godbey PS, Capen RL, Doerschuk CM, Wagner WW: Sites of leukocyte sequestration in the pulmonary microcirculation. J Appl Physiol 1995;79:493497.

44 Wiggs BR, English D, Quinlan WM, Doyle NA, Hogg JC, Doerschuk CM: Contributions of capillary pathway size and neutrophil deformability to neutrophil transit through rabbit lungs. J Appl Physiol 1994;77:463-470.

45 Chien S: Role of blood cells in microcirculatory regulation. Microvasc Res 1985;29:129-151.

46 Downey GP, Doherty DE, Schwab B, Elson EL, Henson PM, Worthen GS: Retention of leukocytes in capillaries: Role of cell size and deformability. J Appl Physiol 1990;69:17671778 .

47 Schmid-Schönbein GW, Sung KLP, Tözeren $\mathrm{H}$, Skalak R, Chien S: Passive mechanical properties of human leukocytes. Biophys $\mathrm{J}$ 1981;36:243-256.

48 Warnke KC, Skalak TC: The effects of leukocytes on blood flow in a model skeletal muscle capillary network. Microvasc Res 1990;40: 118-136.

49 Staub NC, Schultz EL, Albertine KH: Leukocytes and pulmonary microvascular injury. Ann NY Acad Sci 1982;384:332-343.
50 Koyama T, Kikuchi Y, Horimoto M, Kakiuchi Y, Tsushima N, Nitta J: White blood cell adhesion to endothelium and rheological behaviour in microvessels of overinflated frog's lung. Biorheology 1982;19:221-228.

51 Hogg JC, McLean T, Martin BA, Wiggs B: Erythrocyte transit and neutrophil concentration in the dog lung. J Appl Physiol 1988;65: 1217-1225.

52 Downey GP, Worthen GS, Henson PM, Hyde DM: Neutrophil sequestration and migration in localized pulmonary inflammation. Capillary localization and migration across the interalveolar septum. Am Rev Respir Dis 1993;147: 168-176.

53 Tuder RM, Voelkel NF: Pulmonary hypertension and inflammation. J Lab Clin Med 1998; 132:16-24.

54 Kuebler WM, Kuppe H: Zelluläre Pathophysiologie der pulmonalen Hypertonie. Zeitschrift für Herz-, Thorax- und Gefässchirurgie. In press.

55 Kuebler WM, Ying X, Singh B, Issekutz AC, Bhattacharya $\mathrm{J}$ : Pressure is pro-inflammatory in lung venular capillaries. J Clin Invest 1999; 104:495-502.

56 Armstead VE, Minchenko AG, Campbell B, Lefer AM: P-selectin is upregulated in vital organs during murine traumatic shock. FASEB J 1997;11:1271-1279.

57 Dutrochet $\mathrm{MH}$ : Recherches anatomiques et physiologiques sur la structure intime des animaux et des vegetaux, et sur leur motilité. $\mathrm{Pa}$ ris, Baillière et Fils, 1824

58 Cohnheim J: Inflammation. Lectures in general pathology, vol. 1. London, New Syderman Society, 1889

59 Atherton A, Born GV: Quantitative investigations of the adhesiveness of circulating polymorphonuclear leukocytes to blood vessel walls. J Physiol 1972;222:447-474.

60 Atherton A, Born GVR: Relationship between the velocity of rolling granulocytes and that of the blood flow in venules. J Physiol 1973;233: 157-165.

61 Mayrovitz HN, Tuma RF, Wiedeman MP: Leukocyte adherence in arterioles following extravascular tissue trauma. Microvasc Res 1980;20:264-274.

62 Mayrovitz HN: Leukocyte rolling: A prominent feature of venules in intact skin of anesthetized mice. Am J Physiol 1992;262:H157H161.

63 Nolte D, Schmid P, Jäger U, Botzlar A, Roesken F, Hecht R, Uhl E, Messmer K, Vestweber $\mathrm{D}$ : Leukocyte rolling in venules of striated muscle and skin is mediated by P-selectin, not by L-selectin. Am J Physiol 1994;267:H1637H1642.

64 Kuebler WM, Kuhnle GEH, Groh J, Sckell A, Goetz AE: Increased leukocyte sequestration in alveolar capillaries in low flow state is due to retarded entry into narrow capillary segments; in Messmer K, Kuebler WM (eds): 6th World Congress for Microcirculation. Bologna, Monduzzi Editore, 1996, pp 755-759. 
65 Downey GP, Worthen GS: Neutrophil retention in model capillaries: Deformability, geometry, and hydrodynamic forces. J Appl Physiol 1988;65:1861-1871.

66 West JB, Dollery CT, Naimark A: Distribution of blood flow in isolated lung: Relation to vascular and alveolar pressures. J Appl Physiol 1964;19:713-724.

67 Kuebler WM, Abels C, Schuerer L, Goetz AE: Measurement of neutrophil content in brain and lung tissue by a modified myeloperoxidase assay. Int J Microcirc Clin Exp 1996;16:89_ 97.

68 Markos J, Hooper RO, Kavanagh-Gray D, Wiggs B, Hogg JC: Effect of raised alveolar pressure on leukocyte retention in the human lung. J Appl Physiol 1990;69:214-221.

69 Goetz AE, Kuebler WM, Kuhnle G, Groh J, Ney L, Peter K: Positive pressure ventilation promotes leukocyte retention in alveolar capillaries. Anesthesiology 1996;85:A210.

70 Permutt S, Bromberger-Barnea B, Bane HN: Alveolar pressure, pulmonary venous pressure and the vascular waterfall. Med Thorac 1962 . 19:239-260.
71 Permutt S, Riley RL: Hemodynamics of collapsible vessels with tone: The vascular waterfall. $\mathrm{J}$ Appl Physiol 1963;18:924-932.

72 Ley K, Linnemann G, Meinen M, Stoolman LM, Gaehtgens P: Fucoidin, but not yeast polyphosphomannan PPME, inhibits leukocyte rolling in venules of the rat mesentery. Blood 1993;81:177-185.

73 Kuebler WM, Kuhnle GEH, Groh J, Goetz AE: Contribution of selectins to sequestration of leukocytes in pulmonary microvessels by intravital microscopy in rabbits. J Physiol 1997; 501:375-386.

74 Kuebler WM, Borges J, Sckell A, Kuhnle GEH, Bergh K, Messmer K, Goetz AE: Role of Lselectin in leukocyte sequestration in lung capillaries in a rabbit model of endotoxemia. Am J Respir Crit Care Med 2000;161:36-43.

75 Panés J, Perry MA, Anderson DC, Manning A, Leone B, Cepinskas G, Rosenbloom CL, Miyasaka M, Kvietys PR, Granger DN: Regional differences in constitutive and induced ICAM-1 expression in vivo. Am $\mathrm{J}$ Physiol 1995;269:H1955-H1964.
76 Walzog B: Adhesion molecules: The path to a new understanding of acute inflammation. News Physiol Sci 2000;15:107-113.

77 Nakagawa M, Terashima T, D’Yachkova Y, Bondy GP, Hogg JC, Van Eeden SF: Glucocorticoid-induced granulocytosis: Contribution of marrow release and demargination of intravascular granulocytes. Circulation 1998;98:23072313.

78 Novak E, Stubbs SS, Seckman CE, Hearron MS: Effects of a single large intravenous dose of methylprednisolone sodium succinate. Clin Pharmacol Ther 1970;11:711-717.

79 Burton JL, Kehrli ME, Jr., Kapil S, Horst RL: Regulation of L-selectin and CD18 on bovine neutrophils by glucocorticoids: Effects of cortisol and dexamethasone. J Leukoc Biol 1995;57: 317-325.

80 Van Eeden SF, Granton J, Hards JM, Moore B, Hogg JC: Expression of the cell adhesion molecules on leukocytes that demarginate during acute maximal exercise. J Appl Physiol 1999; 86:970-976. 